\title{
Admission blood glucose and short term survival in primary intracerebral haemorrhage: a population based study
}

\author{
R Fogelholm, K Murros, A Rissanen, S Avikainen
}

J Neurol Neurosurg Psychiatry 2005;76:349-353. doi: 10.1136/jnnp.2003.034819

See end of article for authors' affiliations ......................

Correspondence to: Dr R Fogelholm Pappilantie 10 B 8, 02400 Kirkkonummi, Finland; r.fogel@kolumbus.fi

Received

18 December 2003

In revised form

23 June 2004

Accepted 28 June 2004

\begin{abstract}
Background: The role of admission blood glucose level on the prognosis of patients with intracerebral haemorrhage has not been elucidated.

Objective: To examine this association on the basis of an epidemiologically representative patient material.

Methods: 249500 people living in the catchment area of the Central Hospital of Central Finland. The diagnosis of ICH was established if verified by cranial computed tomography (CT) or autopsy.

Results: Of the 416 patients who fulfilled the diagnostic criteria, 30 died before admission and 386 were admitted to the Central Hospital. All 329 patients ( 290 nondiabetics and 39 diabetics) with both admission blood glucose and cranial CT data were included in the study. The mean blood glucose level was $10.6 \mathrm{mmol} / \mathrm{I}$ for nondiabetics who died on the day of onset, $8.6 \mathrm{mmol} / \mathrm{l}$ for those dying during days 1 to 28 , and $6.8 \mathrm{mmol} / \mathrm{I}$ for the 28 day survivors. The corresponding figures for diabetics were $13.9 \mathrm{mmol} / \mathrm{l}$, $12.5 \mathrm{mmol} / \mathrm{l}$, and $9.3 \mathrm{mmol} / \mathrm{l}$. In both nondiabetics and diabetics, patients who died had significantly higher mean glucose than the 28 day survivors $(p<0.0001$ versus $p=0.029)$. However, blood glucose of the surviving diabetics was as high as that of the deceased nondiabetics $(9.3 \mathrm{mmol} / \mathrm{l}$ versus $9.1 \mathrm{mmol} / \mathrm{l})$. In nondiabetics, admission blood glucose was associated with parameters signifying severe stroke; disturbed consciousness, large haematoma volume and shift of cerebral midline structures, and high admission mean arterial pressure. In logistic regression analysis, high admission blood glucose in nondiabetics was a significant predictor of death during the first 28 days of onset (odds ratio $1.22,95 \% \mathrm{Cl}$ 1.07 to 1.40$)$.

Conclusions: High admission blood glucose predicts increased 28 day case fatality rate in both nondiabetic and diabetic patients with $\mathrm{ICH}$. Because high admission blood glucose was associated with markers of severe stroke, we are inclined to support the stress theory; high admission blood glucose is the result of a serious $\mathrm{ICH}$.
\end{abstract}

fulfilled these criteria. Thirty patients died before admission, and of the 386 who were admitted to the Emergency Department of the Central Hospital, 65 died soon after admission on the day of stroke onset.

Admission blood glucose was measured in 347 patients, 345 had cranial CT, and the 329 patients with both examinations were included in this study. Of them, 209 $(64 \%)$ were admitted within $6 \mathrm{~h}$, and $293(89 \%) \leqslant 24 \mathrm{~h}$ of stroke onset. Blood samples for glucose measurement were drawn in $83 \%$ of the patients within the first day, and in $91 \%$ within two days of stroke onset, in $66 \%$ immediately after admission and in $27 \%$ the next morning. CT was performed in $92 \%$ of patients within 3 days of stroke onset. All CT films were available for analysis which included measurement of haematoma volume $(\mathrm{ml})$ and lateral shift $(\mathrm{mm})$ of cerebral midline structures, evaluation of intraventricular or subarachnoidal spread, and hydrocephalus. Haematoma volume was measured by a planimetric computer program. ${ }^{2}$ Blood pressure (BP) was measured on admission; in 94\% within $48 \mathrm{~h}$ of stroke onset. Mean arterial pressure (MAP) was calculated adding one third of the pulse pressure (systolic BP minus diastolic BP) to the diastolic pressure.

The level of consciousness was graded as $(a)$ alert; $(b)$ somnolent or disoriented; and (c) unconscious, whether or not localising pain. The severity of hemiparesis was graded as (a) no paresis; $(b)$ mild to moderate paresis (decreased power

Abbreviations: $\mathrm{BP}$, blood pressure; $\mathrm{CT}$, computed tomography; $\mathrm{ECG}$, electrocardiographic; ICH, intracerebral haemorrhage; MAP, mean arterial pressure frontotemporal ICH in the vicinity of interhemispheric fissure or Sylvian sulcus. During the years concerned, 416 patients 
but able to lift the limb against gravity); and (c) severe paresis (unable to lift the limb against gravity, total paralysis).

The following electrocardiographic (ECG) items were coded; left ventricular hypertrophy, pathological Q wave, atrial fibrillation, left bundle branch block, tachycardia $>100 /$ min, bradycardia $<60 / \mathrm{min}$, ST segment elevation $>2.5 \mathrm{~mm}$, ST segment depression $>1.0 \mathrm{~mm}$, extrasystolia, and negative $\mathrm{T}$ wave.

The history of earlier diseases and anticoagulant use obtained from the patients and/or relatives was confirmed by reviewing the previous medical records. Diabetes was recorded in patients on insulin, oral hypoglycaemic drugs, or on dietary restriction, and hypertension if antihypertensive medication was prescribed. Previous cerebrovascular disease included cerebral infarcts, subarachnoidal and intracerebral haemorrhage, and nonspecified stroke.

\section{Statistical methods}

The results were analysed using Student's $t$ test, $\chi^{2}$ test, Spearman's correlation, and forward stepwise (Wald) logistic regression. All calculations were performed using SPSS (version 10) software.

In logistic regression analysis the 28 day survival (dead $\leqslant 28$ days $=1$, alive $>28$ days $=0$ ) was the dependent variable, and independent variables were those that, considered individually, were significantly associated with the 28 day survival (table 1); anticoagulant treatment, admission MAP, vomiting, consciousness, hemiparesis, shift of cerebral midline structures, blood glucose, and ECG items tachycardia, extrasystoles, and negative $\mathrm{T}$ wave.

Consciousness was dichotomised as conscious (levels $a+b$ ), and unconscious $(c)$, and hemiparesis as no to moderate paresis $(a+b)$, and severe paresis $(c)$. All CT variables were highly significantly intercorrelated, thus, because of easy accessibility, the lateral shift of cerebral midline structures was chosen to represent the CT findings. MAP, blood glucose and shift of midline structures were included as continuous, the others as discrete variables.

Mean substitution was applied for the missing data. The large number of deeply unconscious patients, in whom the evaluation most often is impossible, explains the relatively high proportion (12\%) of missing data on hemiparesis. Admission later than 48 hours of ICH onset explains the $6 \%$ of missing BP values. Two tailed $\mathrm{p}$ values were used, and $\mathrm{p}<0.05$ was considered statistically significant.

\section{RESULTS}

During the first 28 days after onset 127/329 (38.6\%) patients died: 121 from ICH, 3 from pulmonary embolism, and 3 from myocardial infarction. The routine treatment did not include active lowering of high blood glucose levels. Surgical evacuation of the haematoma was performed on 23 patients.

The baseline characteristics of the patients, by 28 day survival, are shown in table 1 . Anticoagulant treatment, high admission MAP, vomiting after stroke onset, disturbed consciousness, severe hemiparesis, large haematoma volume, and lateral shift of cerebral midline structures,

Table 1 Baseline characteristics of the 329 patients, by 28 day survival

\begin{tabular}{|c|c|c|c|}
\hline Variable & $\begin{array}{l}\text { Dead } \leqslant 28 \text { days } \\
(n=127)\end{array}$ & $\begin{array}{l}\text { Alive }>28 \text { days } \\
(n=202)\end{array}$ & p value \\
\hline Men & $63 / 127$ & $95 / 202$ & 0.65 \\
\hline Age & $68.1(1.1)$ & $66.5(0.8)$ & 0.21 \\
\hline \multicolumn{4}{|l|}{ Previous diseases } \\
\hline Hypertension & $54 / 127$ & $77 / 201$ & 0.45 \\
\hline Coronary heart disease & $23 / 127$ & $39 / 201$ & 0.77 \\
\hline Diabetes & $18 / 127$ & $21 / 202$ & 0.30 \\
\hline Previous cerebrovascular disease & $29 / 127$ & $49 / 202$ & 0.77 \\
\hline Anticoagulant treatment & $22 / 126$ & $20 / 201$ & 0.048 \\
\hline Admission MAP (mmHg) & $140.4(2.1)^{*}$ & $128.0(1.4) \dagger$ & $<0.0001$ \\
\hline Vomiting after stroke onset & $44 / 124$ & $41 / 197$ & 0.004 \\
\hline \multicolumn{4}{|l|}{ Consciousness } \\
\hline Alert & 13 & 103 & \\
\hline Somnolent/disoriented & 42 & 85 & $<0.0001$ \\
\hline $\begin{array}{l}\text { Unconscious/stereotypic or no } \\
\text { response to pain }\end{array}$ & 72 & 13 & \\
\hline \multicolumn{4}{|l|}{ Hemiparesis } \\
\hline No paresis & 17 & 68 & \\
\hline Mild to moderate hemiparesis & 18 & 61 & $<0.0001$ \\
\hline Severe hemiparesis/hemiparalysis & 55 & 70 & \\
\hline \multicolumn{4}{|l|}{$\begin{array}{l}\text { Haematoma location } \\
\text { Haemiparalysis }\end{array}$} \\
\hline Supratentorial & 110 & 175 & \\
\hline Infratentorial & 16 & 24 & 0.84 \\
\hline Intraventricular & 1 & 3 & \\
\hline \multicolumn{4}{|l|}{ CT findings } \\
\hline Haematoma volume, mean & $58.9(3.7)$ & $24.9(1.8)$ & $<0.0001$ \\
\hline Lateral shift $(\mathrm{mm})$ of midline & $7.7(0.5)$ & $2.3(0.2)$ & $<0.0001$ \\
\hline \multicolumn{4}{|l|}{ structures } \\
\hline Intraventricular blood & $98 / 127$ & $80 / 202$ & $<0.0001$ \\
\hline Subarachnoidal blood & $47 / 127$ & $12 / 202$ & $<0.0001$ \\
\hline Hydrocephalus & $65 / 127$ & $21 / 202$ & $<0.0001$ \\
\hline \multicolumn{4}{|l|}{ Blood glucose (mmol/l) } \\
\hline Nondiabetic & $9.1(0.3)$ & $6.8(0.2)$ & $<0.0001$ \\
\hline Diabetic & $12.8(1.3)$ & $9.3(0.9)$ & 0.029 \\
\hline \multicolumn{4}{|l|}{ Electrocardiographic findings } \\
\hline $\begin{array}{l}\text { Tachycardia, pulse frequency } \\
>100 / \text { min }\end{array}$ & $30 / 119$ & $27 / 197$ & 0.010 \\
\hline Extrasystoles & $14 / 117$ & $10 / 197$ & 0.026 \\
\hline Negative T wave & $30 / 117$ & $28 / 197$ & 0.012 \\
\hline
\end{tabular}


Table 2 Mean admission blood glucose levels $(\mathrm{mmol} / \mathrm{l})$ among nondiabetics and diabetics, by length of survival

\begin{tabular}{|c|c|c|c|c|}
\hline \multirow[b]{2}{*}{ Outcome } & \multicolumn{2}{|c|}{ Nondiabetics $(n=290$ ) } & \multicolumn{2}{|c|}{ Diabetics $(n=39)$} \\
\hline & Patients & B glucose & Patients & B glucose \\
\hline $\begin{array}{l}\text { Dead } \leqslant 28 \text { days of } \mathrm{ICH} \text { onset } \\
\text { Dead } \leqslant 1 \text { day } \\
\text { Dead } 1-28 \text { days } \\
\text { Alive }>28 \text { days }\end{array}$ & $\begin{array}{r}109 \\
28 \\
81 \\
181\end{array}$ & $\begin{aligned} 9.1 & (0.3)^{*} \\
10.6 & (0.7) \\
8.6 & (0.4) \\
6.8 & (0.2) \dagger\end{aligned}$ & $\begin{array}{r}18 \\
4 \\
14 \\
21\end{array}$ & $\begin{array}{l}12.8(1.3) \ddagger \\
13.9(4.0) \\
12.5(1.3) \\
9.3(0.9) \S\end{array}$ \\
\hline
\end{tabular}

intraventricular and subarachnoid spread, hydrocephalus, high admission blood glucose, and certain ECG abormalities were significantly associated with death during the first 28 days. Diabetes was one of the items that did not differ between survivors and nonsurvivors. The case fatality rates of the nondiabetics $(109 / 290)$ and diabetics (18/39) did not differ significantly $(95 \%$ CI $-25 \%$ to $+8 \%)$.

The mean glucose levels of both nondiabetics and diabetics who died during the first 28 days of stroke onset were significantly higher than of the survivors $(\mathrm{p}<0.0001$ and $\mathrm{p}=0.029$, respectively; table 2 ). In both nondiabetics and diabetics, patients dying during the first day of ICH onset had the highest blood glucose values, followed by those dying during days $1-28$. An important finding was that the mean blood glucose levels of deceased nondiabetics $(9.1 \mathrm{mmol} / \mathrm{l})$ did not differ from that of diabetic survivors $(9.3 \mathrm{mmol} / \mathrm{l})$. In this connection it is worth mentioning that the mean blood glucose level of 11 nondiabetic patients admitted but not included because of early death and missing CT was $10.5 \mathrm{mmol} / \mathrm{l}$.

In nondiabetics, admission blood glucose correlated significantly with admission MAP $\left(\mathrm{r}_{\mathrm{s}}=0.163, \mathrm{p}<0.005\right)$, haematoma volume $\left(\mathrm{r}_{\mathrm{s}}=0.201, \mathrm{p}=0.001\right)$, and shift of cerebral midline structures $\left(\mathrm{r}_{\mathrm{s}}=0.183, \mathrm{p}=0.002\right)$. The mean glucose level was significantly higher among the unconscious patients $(p<0.0001)$, and in the presence of intraventricular or subarachnoid blood and hydrocephalus $(p<0.0001$ to $\mathrm{p}=0.012$ ).

Logistic regression analysis of the 290 nondiabetic patients revealed several independent predictors of death within 28 days of onset (table 3 ). Unconsciousness and lateral shift of cerebral midline structures were the most important, followed by admission blood glucose, anticoagulant treatment and MAP. An analysis that included only the 236 patients with complete data gave otherwise a similar result, except for anticoagulant treatment, which lost its statistical significance.

In another analysis, in which the missing data on hemiparesis of the 35 unconscious patients was substituted with severe hemiparesis instead of mean severity, the results were virtually identical with those presented in table 3.

\section{DISCUSSION}

The mean admission blood glucose level of both nondiabetics and diabetics dying during the first 28 days after stroke onset was statistically significantly higher than among the 28 day survivors. The admission blood glucose level of the diabetic 28 day survivors was of the same magnitude as of the nondiabetics who died within 28 days of ICH onset.

In nondiabetics, there was a significant association between admission blood glucose and MAP, haematoma volume, lateral shift of cerebral midline structures, intraventricular and subarachnoid spread, hydrocephalus, and disturbed consciousness, which are all markers of ICH severity. In logistic regression analysis, high admission blood glucose was one of the significant independent predictors of death within 28 days of onset.

The strengths of this study are the representativeness of the patient material, the strict diagnostic criteria of ICH, and the fairly large number of patients. The patients were traced from the catchment area of one Finnish central hospital with a stable population and a well functioning healthcare system. In short, the study fulfils seven of the eight criteria (the exception being prospective data collection) that are considered as a minimum for good quality studies. ${ }^{3}$

However, there are some problems in the data coding and collecting. Firstly, there was the problem of how to deal with patients dying before or soon after admission, without having had cranial CT and blood glucose measurement, the inclusion criteria for the present study. The 11 nondiabetic patients who died before CT examination and were not included in the study serve as an example. Their mean blood glucose concentration was $10.5 \mathrm{mmol} / \mathrm{l}$, and if they were included, the predictive importance of high admission blood glucose would have been stressed. Another problem group was the deeply unconscious patients, who could not be properly evaluated concerning the severity of hemiparesis. However, substituting the missing values with either the mean severity or severe hemiparesis did not affect the results. Because $\mathrm{HbA}_{\mathrm{lc}}$ was not included in the routine diagnostic examination in the emergency department, there may have been some undiagnosed diabetics within the nondiabetic group. Based on our previous study on ischaemic stroke, this proportion

Table 3 Significant independent predictors of death within 28 days of stroke onset of 290 nondiabetic patients

\begin{tabular}{lcclc}
\hline & B & $\begin{array}{l}\text { Wald } \\
\text { statistic }\end{array}$ & Significance & OR (95\% CI) \\
\hline Unconsciousness (0/1) & 2.550 & 33.0 & 0.000 & $12.80(5.37$ to 30.55$)$ \\
Midline shift (mm) & 0.270 & 29.7 & 0.000 & $1.31(1.19$ to 1.44$)$ \\
Admission blood glucose (mmol/I) & 0.200 & 8.13 & 0.004 & $1.22(1.07$ to 1.40$)$ \\
Anticoagulant treatment (0/1) & 1.379 & 7.34 & 0.007 & $3.97(1.46$ to 10.77) \\
Admission MAP (mmHg) & 0.024 & 7.27 & 0.007 & $1.03(1.01$ to 1.04) \\
Constant & -8.321 & 34.0 & 0.000 & \\
\hline
\end{tabular}

$\mathrm{OR}$, odds ratio; $\mathrm{Cl}$, confidence interval; $\mathrm{MAP}$, mean arterial pressure. 
may be as high as $10 \% .{ }^{4}$ Because we included only the result of the first blood glucose measurement after admission, no conclusions can be drawn about the course of blood glucose level after admission.

The prevalence $(11.9 \%)$ of diabetics in this study corresponds well with the pooled prevalence $(11.2 \%)$ of previous studies, which included 1805 ICH patients, ${ }^{5-11}$ but is lower than the $17 \%$ obtained in another recent study. ${ }^{12}$ In diabetics, the risk of ICH compared with nondiabetics has been calculated as 1.30 (95\% CI 1.02 to 1.67$).{ }^{13}$ Estimates of the impact of diabetes on ICH outcome have varied from increased risk of early/hospital death, ${ }^{10}{ }^{11}$ death or dependency at 1 year after stroke, ${ }^{7}$ to no association with the 30 day mortality. ${ }^{8}$ In noncomatose patients, diabetes has appeared as an independent predictor of 30 day and 3 month mortality. ${ }^{12}$

If hyperglycaemia per se has an adverse effect on stroke outcome, a universally poorer early outcome would be expected for diabetics. This was not the case in our study, and the surviving diabetics actually had slightly higher blood glucose than the deceased nondiabetics. However, firm conclusions are difficult to make because of the small number of diabetics.

Compared with ischaemic stroke there are relatively few studies on the association between admission blood glucose level and prognosis of ICH. Melamed was the first to emphasise the association of reactive hyperglycaemia $(>6.7 \mathrm{mmol} / \mathrm{l})$ with poor outcome in nondiabetic patients. ${ }^{14}$ Hyperglycaemia was considered reactive because it was transient and stabilised within 3.7 to 7.8 days in nondiabetics and diabetics, respectively. The prognostic value of admission blood glucose level in ICH has since been analysed in several studies with relatively few patients. ${ }^{815-18}$ In univariate analysis, high admission blood glucose level, nondiabetics and diabetics combined, has predicted a poor early survival rate. In multivariate analysis, admission blood glucose $\geqslant 8 \mathrm{mmol} / \mathrm{l}$ has appeared as a significant independent predictor of death within 2 days of stroke onset. ${ }^{16}$ In a recent large study of 764 patients, diabetics who died $\leqslant 30$ days of onset had significantly higher blood glucose levels than the survivors, and among the noncomatose nondiabetic patients, hyperglycaemia ( $\geqslant 7.2 \mathrm{mmol} / \mathrm{l}$ ) was a significant independent predictor of death within 30 days of onset. ${ }^{12}$ In a large systematic review of prognostic models in acute stroke, nonhaemorrhagic and haemorrhagic combined, high blood glucose appeared as an independent predictor of death within 30 days of stroke onset in only every fourth study. ${ }^{3}$

The association of high admission blood glucose with poor early survival was evident also in this study. In univariate analysis, both nondiabetic and diabetic patients dying within 28 days of onset had significantly higher blood glucose values than the survivors. Among nondiabetics, high blood glucose was a significant independent predictor of death within 28 days of onset.

Hyperglycaemia in acute stroke has in some studies been considered as a manifestation of premorbid diabetic glucose metabolism, ${ }^{19-21}$ a stress reaction or associated with other mechanisms. $^{22} 23$ The amount of evidence supporting in particular the stress hypothesis of poststroke hyperglycaemia is increasing. Firstly, hyperglycaemia is transient, increasing during the first 12 hours, ${ }^{24}$ and decreasing and stabilising within 1 to a few weeks. ${ }^{14}{ }^{25-27}$ Secondly, the glycolysated haemoglobin $\left(\mathrm{HbA}_{1 \mathrm{c}}\right)$ concentration reflecting the premorbid glucose levels does not correlate with poststroke glucose values, stroke severity, cerebral infarct volume or outcome. ${ }^{46-29}$ Thirdly, poststroke blood glucose in nondiabetics is strongly associated with early survival, ${ }^{1}{ }^{41427-29}$ and fourthly, an association between the stress hormones cortisol and/or catecholamines and stroke severity, volume of cerebral lesion, blood glucose, and/or outcome has been observed..$^{29}{ }^{30}$ We must, however, remember that these studies are based on patient cohorts including those with ischaemic strokes alone, or a patient mix with a minority of haemorrhagic strokes.

In both the present and the Italian study of Passero et al, ${ }^{12}$ high admission blood glucose was associated with variables signifying the severity of stroke, such as initial MAP, haematoma volume, shift of cerebral midline structures, intraventricular extension, and disturbed consciousness. These all point to hyperglycaemia being a stress reaction to a serious disease. Therefore, we question the possible benefits of active lowering of high blood glucose values after ICH. To obtain a definitive answer, a randomised controlled trial is needed.

\section{CONCLUSIONS}

In this study, the mean admission blood glucose concentrations of both nondiabetics and diabetics dying during the first 28 days after stroke onset were significantly higher than of the survivors. In addition, the mean blood glucose level of the diabetics surviving over 28 days was as high as among the nondiabetics who died within 28 days of stroke onset. We conclude therefore that the level of blood glucose per se does not affect the outcome, and that high admission blood glucose in primary intracerebral haemorrhage is most probably a stress response.

\section{ACKNOWLEDGEMENTS}

We would like to thank Dr C Franke for his valuable comments during the preparation of this manuscript.

\section{Authors' affiliations}

R Fogelholm, Department of Neurology, University of Helsinki, Helsinki, Finland

K Murros, Department of Neurology, Jorvi Hospital, Finland

A Rissanen, Department of Neurology, Central Hospital of Central Finland, Jyväskylä, Finland

S Avikainen, Department of Neurology, Kainuu Central Hospital, Kajaani, Finland

Competing interests: none declared

\section{REFERENCES}

1 Capes SE, Hunt D, Malmberg K, et al. Stress hyperglycemia and prognosis of stroke in nondiabetic and diabetic patients. A systematic overview. Stroke $2001 ; 32: 2426-32$

2 Fogelholm R, Nuutila M, Vuorela A-L. Primary intracerebral haemorrhage in the Jyväskylä region, Central Finland, 1985-89: incidence, case fatality rate, and functional outcome. J Neurol Neurosurg Psychiat 1992;55:546-52.

3 Counsell C, Dennis M. Systematic review of prognostic models in patients with acute stroke. Cerebrovasc Dis 2001;12:159-70.

4 Murros K, Fogelholm R, Kettunen S, et al. Blood glucose, glycosylated haemoglobin, and outcome of ischemic brain infarction. J Neurol Sci 1992;111:59-64.

5 Woo E, Chan YW, Yu YL, et al. Admission glucose level in relation to mortality and morbidity outcome in 252 stroke patients. Stroke 1988; 19:185-91.

6 Jörgensen FS, Nakayama H, Raaschou HO, et al. Stroke in patients with diabetes. The Copenhagen Stroke Study. Stroke 1994;25:1977-84.

7 Juvela S. Risk factors for impaired outcome after spontaneous intracerebral hemorrhage. Arch Neurol 1995;52:1193-1200.

8 Masè $\mathrm{G}$, Zorzon M, Biasutti $\mathrm{E}$, et al. Immediate prognosis of primary intracerebral hemorrhage using an easy model for the prediction of survival. Acta Neurol Scand 1995;91:306-9.

9 Moulin T, Tatu L, Crépin-Leblond T, et al. The Besancon Stroke Registry: An acute stroke registry of 2,500 consecutive patients. Eur Neurol 1997;38:10-20.

10 Wong KS, for the Asian Acute Stroke Advisory Panel. Risk factors for early death in acute ischemic stroke and intracerebral hemorrhage. A prospective hospital-based study in Asia. Stroke 1999;30:2326-30.

11 Arboix A, Massons J, Garcia-Eroles L, et al. Diabetes is an independent risk factor for in-hospital mortality from acute spontaneous intracerebral hemorrhage. Diabetes Care 2000;23:1527-32.

12 Passero S, Ciacci G, Ulivelli M. The influence of diabetes and hyperglycemia on clinical course after intracerebral hemorrhage. Neurology 2003;61:1351-6. 
13 Ariesen MJ, Claus SP, Rinkel GJE, et al. Risk factors for intracerebral hemorrhage in the general population. A systematic review. Stroke 2003;34:2060-6.

14 Melamed E. Reactive hyperglycaemia in patients with acute stroke. J Neurol Sci 1976;29:267-75.

15 Tuhrim S, Dambrosia JM, Price TR, et al. Intracerebral hemorrhage: External validation and extension of a model for prediction of 30-day survival. Ann Neurol 1991;29:658-63.

16 Franke CL, van Swieten JC, Algra A, et al. Prognostic factors in patients with intracerebral haematoma. J Neurol Neurosurg Psychiat 1992;55:653-7.

17 Hemphill JC, Bonovich DC, Besmertis L, et al. The ICH Score. A simple, reliable grading scale for intracerebral hemorrhage. Stroke 2001;32:891-7.

18 Cheung RT, Zou L-Y. Use of the original, modified, or new intracerebral hemorrhage score to predict mortality and morbidity after intracerebral hemorrhage. Stroke 2003;34:1717-22.

19 Oppenheimer SM, Hoffbrand BI, Oswald GA, et al. Diabetes mellitus and early mortality from stroke. BMJ 1985;291:1014-15

20 van Kooten F, Hoogerbrugge N, Naarding P, et al. Hyperglycemia in the acute phase of stroke is not caused by stress. Stroke 1993:24:1129-32.

21 Oppenheimer SM. Plasma cortisol as a measure of stress response in acute stroke. Stroke 1990;21:1376.
22 Slowik A, Turaj W, Pankiewicz J, et al. Hypercortisolemia in acute stroke is related to the inflammatory response. J Neurol Sci 2002;196:27-32.

23 Weir CJ, Murray GD, Dyker AG, et al. Is hyperglycaemia an independent predictor of poor outcome after acute stroke? Results of a long term follow up study. BMJ 1997;314:1303-6.

24 Christensen H, Boysen G. Blood glucose increases early after stroke onset. A study on serial measurements of blood glucose in acute stroke. Eur J Neurol 2002:9:297-301.

25 Candelise L, Landi G, Orazio EN, et al. Prognostic significance of hyperglycemia in acute stroke. Arch Neurol 1985;42:661-3.

26 Power MJ, Fullerton KJ, Stout RW. Blood glucose and prognosis of acute stroke. Age Ageing 1988;17:164-70.

27 O'Neill PA, Davies I, Fullerton KJ, et al. Stress hormone and blood glucose response following acute stroke in the elderly. Stroke 1991;22:842-7.

28 Gray CS, Taylor R, French JM, et al. The prognostic value of stress hyperglycaemia and previously unrecognized diabetes in acute stroke. Diabetic Med 1987;4:237-40.

29 Tracey F, Crawford VLS, Lawson JT, et al. Hyperglycaemia and mortality from acute stroke. Q J Med 1993;86:439-46.

30 Murros K, Fogelholm R, Kettunen S, et al. Serum cortisol and outcome of ischemic brain infarction. J Neurol Sci 1993;116:12-17.

\section{Register now!}

10th European Forum on Quality Improvement in Health Care 13-15 April 2005, ExCel Conference Centre, London For further information on how to register please go to: http://www.quality.bmipg.com 